\title{
CALCULATION OF ELECTROMAGNETIC FIELDS IN INHOMOGENEOUS MEDIA FOR SELECTION OF PROTECTIVE COATINGS
}

The aim of the work is to develop a method for high-frequency EMFs calculation in terms of the modified vector potential and to use it for choice of the parameters of the layered absorbing coatings that provide effective absorption of radio wave radiation. Methodology. A method for calculation of electromagnetic fields in inhomogeneous media is described. It is performed in terms of the modified magnetic potential at presented a plane electromagnetic wave as an incident and reflected one. To reduce the computational domain size, additional uniaxially perfectly matched layers ensuring fast and non-reflective attenuation of electromagnetic field (EMF) strengths are used at its boundaries. It is supposed that electrical parameters of such layers have not only resistive, but also magnetic losses. Results. Modification of the known methods for dividing the wave into the incident and reflected, as well as introducing uniaxially perfectly matched layers at the domain boundaries and formulation of the problem in terms of the modified vector potential, provide a possibility to solve the problem of the electromagnetic wave incidence onto heterogeneous media at reduced memory and counting time compared to the formulation tasks through the EMF strengths. Practical value. The described method was used to select parameters of radio-absorbing coatings, application of which on conductive bodies reduces the reflections from them of the incident electromagnetic waves. This provides a possibility to choose the electrical parameters of layered coatings with active losses, as well as magnetic losses, which provide a decrease of the reflected waves amplitude by an order of magnitude or more. Originality. For the first time, the problem of calculating the incidence of an electromagnetic wave on an inhomogeneous medium with active electrical and magnetic losses was formulated in terms of the modified vector potential. The parameters of a multilayer lossy coating, which ensures decrease of the reflected EMF wave strengths by an order of magnitude or more are determined. References 11, figures 3.

Key words: electromagnetic field, inhomogeneous media, modified vector magnetic potential, finite integration method, uniaxially perfectly matched layers.

Описаний метод розрахунку електромагнітних полів в неоднорідних середовищах, виконаний в термінах модифікованого магнітного потенціалу при поділі плоскої електромагнітної хвилі на падаючу $і$ відбиту. Для зменшення габаритів розрахункової області на їі границях введені додаткові одновісне ідеально поглинаючі шари, щио забезпечують швидке і безвідбивне загасання напруженостей електромагнітних полів (ЕМП). Особливістю таких шарів с вибір їх електричних параметрів такими, ццоб забезпечити наявність в них не тільки резистивних, але $i$ магнітних втрат. Математичне моделювання процесів при падінні ЕМП на провідне середовище, перед яким поміщені покриття 3 подібними властивостями показало можсливість ефективного загасання в них ЕМП радіочастотного діапазону. В результаті проведених досліджень обрані параметри покриттів, цо забезпечують мінімальне відбиття падаючих електромагнітних хвиль. Бібл. 11, рис. 3.

Ключові слова: електромагнітне поле, неоднорідні середовища, модифікований векторний магнітний потенціал, метод кінцевого інтегрування, ідеально узгоджені поглинаючі граничні шири.

Описан метод расчета электромагнитных полей в неоднородных средах, выполненный в терминах модифицированного магнитного потенциала при разделении плоской электромагнитной волны на падающую и отраженную. Для уменьшения габаритов расчетной области на ее границах введены дополнительные одноосно идеально поглощающие слои, обеспечивающие быстрое и безотражательное затухание напря⿻енностей электромагнитных полей (ЭМП). Особенностью таких слоев является то, что их электрические параметры выбраны такими, чтобы обеспечить наличие в них не только резистивных, но и магнитных потерь. Математическое моделирование процессов при падении ЭМП на проводящую среду, перед которой помещены покрытия с подобными свойствами, показало возможность эффективного затухания в них ЭМП радиочастотного диапазона. В результате проведенных исследований выбраны параметры покрытий, обеспечивающих минимальное отражсене падающих электромагнитных волн. Библ. 11, рис. 3.

Ключевые слова: электромагнитное поле, неоднородные среды, модифицированный векторный магнитный потенциал, метод конечного интегрирования, идеально согласованные поглощающие граничные слои.

Introduction. When solving a number of problems of theoretical electrical engineering and electrophysics, the problems of calculating electromagnetic fields (EMF) arise, including when a wave is incident on inhomogeneous media with flat interfaces. Such problems have to be solved, for example, when choosing the parameters of protective radar absorbing coatings of extended conductive objects from high-frequency radiation. Since in this case the application of analytical methods [1] is impossible, the development of numerical methods is necessary. Taking into account the flat geometry of the systems under consideration, the use of finite-difference methods seems most effective (see, for example, $[2,3])$. To reduce the order of the system of equations being solved, the problem formulation in terms of the modified vector magnetic potential can be used [4]. In contrast to the traditional formulation of electromagnetic fields through EMF strengths, this approach allows to reduce the required computer resources due to the fact that in the calculation 3 components of the modified vector magnetic potential are unknown, rather than 3 components of the electric field strength and 3 components of the magnetic field strength [4].

If there are several media interfaces with flat interfaces, it seems efficient to use the numerical finite integration method (FIM) [5]. The essence of this method is to impose a rectangular computational mesh on the considered region and integrate Maxwell equations over the volumes or faces of its cells. Thus, equations to be solved are obtained using conservation laws. Moreover, the formulation of the calculation problem using the finite integration method in terms of a modified vector magnetic potential with a special choice of the computational mesh ensures the automatic fulfillment of conditions at the media interfaces for the vectors of strengths and the flux density of the EMF $[6,7]$.

To limit the calculation region when determining the EMF in open areas when formulating the problem using EMF strengths, the so-called UPML (uniaxially perfectly 
matched layers) are used [8]. To solve the problems associated with the propagation of high-frequency oscillations in inhomogeneous media with losses, it seems important to develop UPML in relation to the formulation of problems in terms of a modified vector magnetic potential.

The goal of the work is to develop a method for calculating high-frequency EMFs in lossy media using modified vector potential and UPML.

Definition of the problem of calculating the process of incidence of a plane electromagnetic wave on layered media. In order to reduce the number of equations in solving the problem of calculating EMF, we use the socalled modified vector magnetic potential $\boldsymbol{A}$ [4].

In the absence of external sources of electric charge, an additional condition when using the scalar electric $(\varphi)$ and the vector magnetic $(\boldsymbol{A})$ potentials, instead of electric $(\boldsymbol{E})$ and magnetic $(\boldsymbol{H})$ field strengths, the gauging condition $\varphi=0$ can be chosen (see, for example, [1]). Then vectors of the magnetic flux density $\boldsymbol{B}$ and the electric field strength $\boldsymbol{E}$ are expressed through $\boldsymbol{A}$ in the form:

$$
\begin{gathered}
\boldsymbol{B}=\operatorname{rot} \boldsymbol{A}=\mu \mu_{0} \boldsymbol{H} ; \\
\boldsymbol{E}=-\frac{\partial \boldsymbol{A}}{\partial t} .
\end{gathered}
$$

In order for the reflectionless EMF attenuation to occur upon falling onto the radar absorbing coating, it is necessary to ensure the presence of losses not only related to the active conductivity of the medium, but also magnetic losses.

The second Maxwell equation, taking into account magnetic losses, has the form $[9$, p. 69]:

$$
\operatorname{rot} \boldsymbol{E}=-\left(\frac{\partial \boldsymbol{B}}{\partial t}+\gamma_{\mu} \boldsymbol{H}\right)
$$

where $\gamma_{\mu}$ are the equivalent magnetic losses $[\Omega / \mathrm{m}]$.

Taking into account (1), rewrite the right-hand side of (3) in the form:

$$
\frac{\partial \boldsymbol{B}}{\partial t}+\gamma_{\mu} \boldsymbol{H}=\operatorname{rot} \frac{\partial \boldsymbol{A}}{\partial t}+\frac{\gamma_{\mu}}{\mu \mu_{0}} \operatorname{rot} \boldsymbol{A} .
$$

Then write (3) as

$$
\operatorname{rot} \boldsymbol{E}=-\operatorname{rot} \frac{\partial \boldsymbol{A}}{\partial t}-\frac{\gamma_{\mu}}{\mu \mu_{0}} \operatorname{rot} \boldsymbol{A},
$$

whence, for piecewise homogeneous media, $\boldsymbol{E}$ can be expressed in terms of $\boldsymbol{A}$ as follows:

$$
\boldsymbol{E}=-\frac{\partial \boldsymbol{A}}{\partial t}-\frac{\gamma_{\mu}}{\mu \mu_{0}} \boldsymbol{A} .
$$

Here, the first Maxwell equation

$$
\operatorname{rot} \boldsymbol{H}=\gamma \boldsymbol{E}+\frac{\partial \boldsymbol{D}}{\partial t},
$$

where $\boldsymbol{D}$ is the electric field induction; $\gamma$ is the electrical conductance takes the form:

$$
\operatorname{rot} \frac{\operatorname{rot} \boldsymbol{A}}{\mu \mu_{0}}=-\gamma \frac{\partial \boldsymbol{A}}{\partial t}-\varepsilon_{0} \varepsilon \frac{\partial^{2} \boldsymbol{A}}{\partial t^{2}}-\frac{\gamma \gamma_{\mu}}{\mu \mu_{0}} \boldsymbol{A}-\frac{\gamma_{\mu} \varepsilon_{0} \varepsilon}{\mu \mu_{0}} \frac{\partial \boldsymbol{A}}{\partial t}
$$

To obtain a numerical solution for the vector potential, the considered region was divided into parallelepiped cells (Fig. 1) so that the nodes of the computational mesh $(i, j, k)$ lay at the interfaces of the media. It was assumed that the electrical properties of the medium within each of the cells are homogeneous.

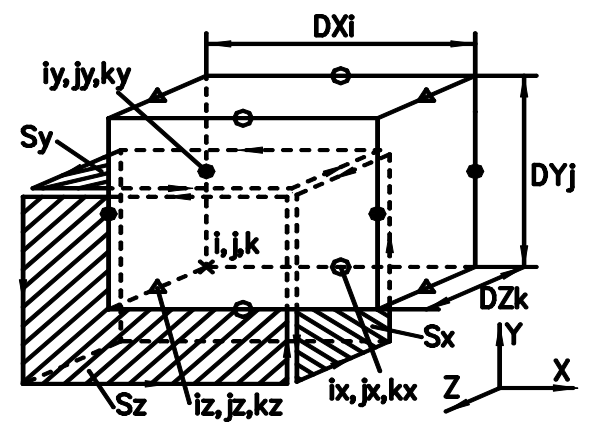

Fig. 1. Cell of the calculation scheme

The equation to be solved was obtained by integrating (5) over sections perpendicular to the coordinate axes. Then the equations for the components of the vector $\boldsymbol{A}$ can be written as a result of integration of (5) over the sections $S_{x}, S_{y}, S_{z}$ (see Fig. 1) and using the Stokes theorem. So for $A_{y}-$ the y-th component of the vector $\boldsymbol{A}$ - we obtain:

$$
\begin{aligned}
& \oint_{l_{y}} \frac{\operatorname{rot} \boldsymbol{A}}{\mu \mu_{0}} d \boldsymbol{l}=\int_{S_{y}}\left(-\gamma \frac{\partial A_{y}}{\partial t}-\varepsilon_{0} \varepsilon \frac{\partial^{2} A_{y}}{\partial t^{2}}-\right. \\
& \left.-\frac{\gamma \gamma_{\mu}}{\mu \mu_{0}} A_{y}-\frac{\gamma_{\mu} \varepsilon_{0} \varepsilon}{\mu \mu_{0}} \frac{\partial A_{y}}{\partial t}\right) d S,
\end{aligned}
$$

where $l_{y}$ is the contour covering the area $S_{y}$.

As a result of integration of (5) over the corresponding areas: $S_{x}$ for $A_{x}$ and $S_{z}$ for $A_{z}$ (see Fig. 1), similar expressions are written for the remaining components of the vector potential. Passing to the difference form of writing, we obtain a system of equations to be solved.

Features of the numerical calculation of EMF using a modified vector magnetic potential. When calculating electromagnetic processes when a plane electromagnetic wave having a finite length and harmonic filling is incident on objects, the problem arises of setting conditions for the strengths and potential of the EMP at the boundaries of the computational domain. To limit the computational domain when applying finite-difference methods of numerical computation, the introduction of so-called uniaxial perfectly matched layers (UPML) at the external boundaries of the computational domain is usually used, which ensure fast and reflectionless attenuation of the EMF. However, in this case, for the problem formulation under consideration, it is impossible to specify zero boundary conditions for the EMF potentials and strengths at the external UPML boundaries. The fact is that in addition to the reflected wave, which can really be assumed to be equal to zero at a sufficient distance from the object causing it, there is also an incident wave, which over time can be non-equal to zero and at a sufficient distance from the object. To solve this problem, a representation of the electromagnetic wave in the form of the sum of the incident and reflected waves is used. The propagation of both of these waves is described by the same Maxwell equations. In this case, the computational domain is also divided into two zones: the first (I), the inner, in which the studied object is located, and the second (II), the outer, located between the boundaries of the 1 st region and the UPML inner borders. Here, in zone I, the propagation of the total wave is calculated, which contains both the incident and reflected waves. In zone II, only the propagation of the reflected wave is calculated. At the boundaries of zones I and II, the transition from calculating 
only the reflected and total waves is taken into account. At the outer boundaries of $U P M L$, zero conditions can be used for the potentials and strengths of the EMF, since they relate only to the reflected wave.

In [9], the solution of the problem of propagation and reflection of electromagnetic waves is presented using the described approach when using the Yee algorithm to calculate the components of the electric and magnetic field strengths. This approach was applied to solve the problem formulated in terms of a modified vector potential using the finite integration method. In this case, terms appearing in difference schemes containing the known values of the vector potential corresponding to the incident wave. The addition or subtraction of these terms when writing the equations to be solved for the nodes adjacent to the interface of subregions I and II allowed to implement the approach described above. Since the values of the incident wave at each moment of time and for each node of the calculation scheme are known, they are transferred to the right side of the equations. Such terms are added to the right sides of the difference equations written for nodes lying on the boundaries of subregions I and II, and are subtracted from the right sides of difference equations written for nodes located in II in planes in front of the boundaries of subregions I and II.

The introduction of UPML in calculating the propagation of an electromagnetic wave in terms of a modified vector magnetic potential requires a different approach than when solving through electric and magnetic field strengths. This is due to the fact that the parameter $s_{\mu}$

$$
s_{\mu}=1+\frac{\gamma_{\mu}}{j \omega \mu \mu_{0}}
$$

which is chosen equal to $S_{\varepsilon}$

$$
s_{\varepsilon}=1+\frac{\gamma}{j \omega \varepsilon \varepsilon_{0}},
$$

when formulating the problem through $\underline{A}$ appears in the denominator of the equation to be solved. Therefore, its conversion during the transition from the frequency domain to the time domain is impossible. To use UPML in such a formulation, it is proposed to use a medium in which $\varepsilon \cdot \omega$ and $\mu \cdot \omega$ are much smaller than $\gamma$ and $\gamma_{\mu}$, respectively, as absorbing layers. To ensure the constancy of the propagation speed of electromagnetic waves and the absence of reflections when the EMF falls on the UPML layers, it is necessary $s_{\mu}=s_{\varepsilon}$. At $\mu \cdot \omega<<\gamma_{\mu}$ and $\varepsilon^{*} \omega<<\gamma$ :

$$
\begin{aligned}
& s_{\varepsilon} \approx \frac{\gamma}{j \omega \varepsilon \varepsilon_{0}}, \\
& s_{\mu} \approx \frac{\gamma_{\mu}}{j \omega \mu \mu_{0}} .
\end{aligned}
$$

Then from $(9,10)$ we obtain:

$$
\frac{\gamma \mu}{\mu \mu_{0}}=\frac{\gamma}{\varepsilon \varepsilon_{0}} \text {. }
$$

Hence the relation between $\gamma$ and $\gamma_{\mu}$ :

$$
\gamma_{\mu}=\gamma \frac{\mu \mu_{0}}{\varepsilon \varepsilon_{0}} \approx 0.142 \cdot 10^{6} \gamma \frac{\mu}{\varepsilon}[\Omega / \mathrm{m}]
$$

We obtain expressions for EMF in UPML layers by writing (6) through complexes (indicated by an underscore of the corresponding value) and taking into account (7), (8):

$$
\begin{aligned}
& \oint_{l_{y}} \frac{\operatorname{rot} \underline{\boldsymbol{A}}}{\mu_{0} \mu} d \boldsymbol{l}=\int_{S_{y}}\left(-j \omega \gamma \underline{A}_{y}-(j \omega)^{2} \varepsilon_{0} \varepsilon \underline{A}_{y}-\right. \\
& \left.-\frac{\gamma \gamma \mu}{\mu_{0} \mu} \underline{A}_{y}-j \omega \frac{\varepsilon_{0} \varepsilon}{\mu_{0} \mu} \gamma_{\mu} \underline{A}_{y}\right) d S= \\
& =\int_{S_{y}}\left[-(j \omega)^{2} \varepsilon_{0} \varepsilon \underline{A}_{y}\left(1+\frac{\gamma}{j \omega \varepsilon_{0} \varepsilon}\right)-\right. \\
& \left.-j \omega \frac{\varepsilon_{0} \varepsilon}{\mu_{0} \mu} \gamma_{\mu} \underline{A}_{y}\left(1+\frac{\gamma}{j \omega \varepsilon_{0} \varepsilon}\right)\right] d S= \\
& =-\int_{S_{y}}(j \omega)^{2} \varepsilon_{0} \varepsilon \underline{A}_{y} s_{\varepsilon} s_{\mu} d S .
\end{aligned}
$$

Dividing both parts of the resulting expression into $\widehat{s}_{\mu}$, we write:

$$
\oint_{l_{y}} \frac{\operatorname{rot} \underline{\boldsymbol{A}}}{\mu_{0} \mu s_{\mu}} d \boldsymbol{l}=-\int_{S_{y}}(j \omega)^{2} \varepsilon_{0} \varepsilon \underline{A}_{y} s_{\varepsilon} d S .
$$

In view of (9), (10), we transform the last expression to the form:

$$
\oint_{l_{y}} \frac{j \omega \cdot \operatorname{rot} \underline{\boldsymbol{A}}}{\gamma_{\mu}} d \boldsymbol{l}=-\int_{S_{y}} j \omega \gamma \underline{A}_{y} d S
$$

Then, in the last expression, we move from the complex form of writing to the functions of time:

$$
\oint_{l_{y}} \frac{\operatorname{rot}[\partial \boldsymbol{A} / \partial t]}{\hat{\gamma}_{\mu}} d \boldsymbol{l}=-\int_{S_{y}} \hat{\gamma} \cdot \frac{\partial A_{y}}{\partial t} d s .
$$

A numerical solution was obtained by writing equations of the form (6), (12) for nodes of the computational mesh and replacing the differential operators in them by difference analogues. To solve the obtained system of equations, the sweep method was used (for more details see $[6,7]$ ).

To evaluate the effectiveness of the proposed method of introducing $U P M L$, numerical experiments were carried out to calculate electromagnetic processes in the case of a plane electromagnetic wave incident on a perfectly conducting sheet. It was assumed that the EMF with $|\boldsymbol{E}|=1 \mathrm{~V} / \mathrm{m}$ from time $t=0$ falls in the direction of the $\mathrm{Oz}$ axis onto a conductive sheet whose thickness is $d=3 \cdot \Delta$ (where $\Delta$ is the spatial step). It is believed that this sheet is located in the $z=$ const plane and has dimensions in the $x$ and $y$ coordinates many orders of magnitude greater than the wavelength of the incident EMF. When calculating at the boundaries of the computational domain in the directions of the $O x, O y$, and $\mathrm{Oz}$ axes zero conditions were used for the vector potential of the reflected waves. The frequency of the incident EMF was assumed to be $10 \mathrm{GHz}$. In the calculations, the time step was set equal to $\Delta_{t}=T / 200, \Delta=c \cdot T / 200$ $\left(c=3 \cdot 10^{8} \mathrm{~m} / \mathrm{s}\right)$. The $U P M L$ parameters were as follows: the number of layers $N=10, \gamma$ varied according to the exponential law with an exponent of 3 [8] from $35 \mathrm{~S} / \mathrm{m}$ at the inner UPML boundary, $\gamma_{\mu}$ varied depending on $\gamma$ in accordance with (11). The dimensions of the computational domain in the direction of the $\mathrm{Oz}$ axis are $Z_{\max }=0.5 \cdot \lambda$ (where $\lambda$ is the wavelength), and the number of steps in reflection zone II is 10 .

Figure 2 shows the calculated time sweeps of the reflected (scattered) electric field strength $\left|\boldsymbol{E}_{\text {scat }}\right|$ when a plane electromagnetic wave falls on a conductive sheet. 
As can be seen from the Figure, due to the fact that UPML layers with the parameters described above are located at the boundaries of the computational domain, the relative error in calculating the strength $\left|\boldsymbol{E}_{\text {scat }}\right|$ does not exceed $3 \%$, despite a significant truncation of the length of the computational domain.

Thus, a technique for calculating the propagation of an electromagnetic wave in media with magnetic losses in terms of a modified vector magnetic potential is described. This ensures the introduction of UPML at the boundaries of the computational domain, which was previously possible only when formulating the problem through EMF strengths.

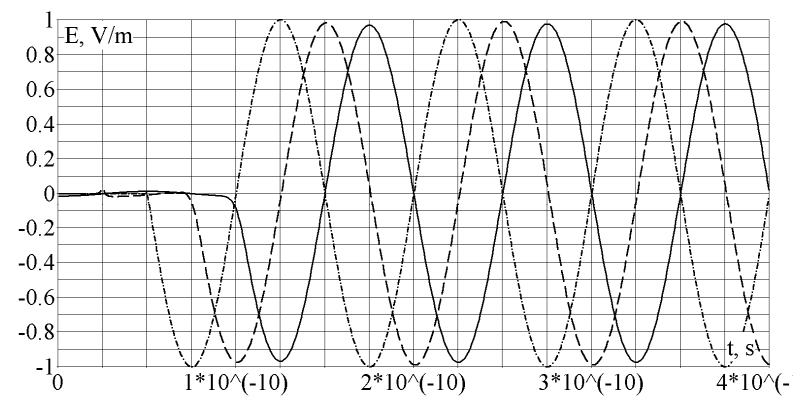

Fig. 2. Calculated dependencies $\left|\boldsymbol{E}_{\text {scat }}\right|(t)$ for nodes located at different distances $(z)$ from the conducting sheet: $z=\lambda(-)$,

$$
-z=0.5 \cdot \lambda(---),-z=0(-\cdot-\cdot-)
$$

Mathematical modelling of EMF fall on layered coatings with dielectric and magnetic losses. In some cases, various dielectrics with low values of the reflection coefficient and high values of the absorption coefficient of radio waves are used as protective coatings from highfrequency radiation. Scopes of radar absorbing coatings are various. So, they are used to create screens for radio receivers, to protect biological objects from electromagnetic radiation, to equip special research chambers, etc. A large number of works have been devoted to this issue (see, for example, $[10,11])$, but the problem of choosing coating parameters remains relevant, since the question of a significant decrease in the amplitude of waves reflected from conductive objects has not been completely resolved.

Figure 3 shows the calculated time sweeps of the electric field strength when a plane electromagnetic wave falls on a conductive sheet, before which a radar absorbing coating is placed with the following parameters: the 1st layer (closest to the conductive sheet) $-\varepsilon=\mu=300, \gamma=315 \mathrm{~S} / \mathrm{m}$, the next layer $-\varepsilon=\mu=100$, $\gamma=275 \mathrm{~S} / \mathrm{m}$, the last layer $-\varepsilon=\mu=60, \gamma=17.5 \mathrm{~S} / \mathrm{m}\left(\gamma_{\mu}\right.$ changed depending on $\gamma$ in accordance with (11)). As can be seen from the Figure, due to the attenuation of the electromagnetic wave in the coating layers, the reflection from the conducting sheet in the steady state does not exceed $10 \%$ of the initial reflection level.

\section{Conclusions.}

1. A method for calculating the propagation of an electromagnetic wave in lossy media located in open areas at formulating the problem in terms of a modified vector magnetic potential and using $U P M L$ the implementation of which allows to reduce the memory and calculation time compared to formulation of the problem through EMF strengths is proposed and tested by comparison with an analytical solution.
2. The proposed calculation method is the theoretical basis for developing a method for selecting parameters of radar absorbing coatings with electric and magnetic losses, the application of which to conductive objects provides a significant reduction in the amplitude of the reflected radio waves.

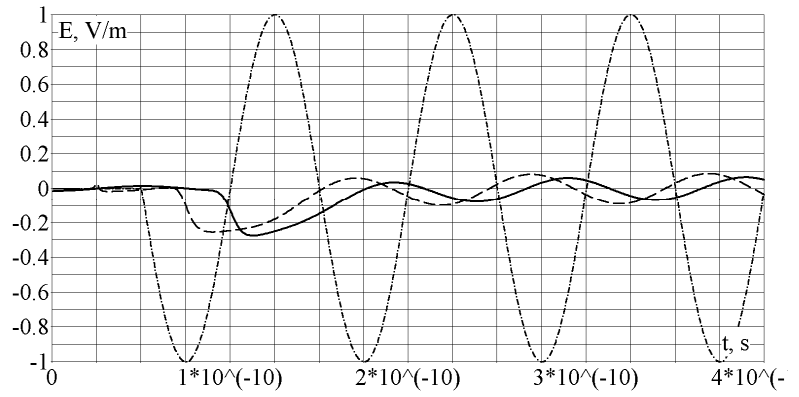

Fig. 3. Calculated dependencies $\left|\boldsymbol{E}_{\text {scat }}\right|(t)$ in the presence in front of the conductive sheet of the radar absorbing coating for nodes

located at different distances $(z)$ from the conductive sheet:

$$
z=\lambda(-),-z=0.5 \cdot \lambda(---),-z=0(-\cdot-\cdot-)
$$

\section{REFERENCES}

1. Stratton J.A. Electromagnetic theory. NJ, IEEE Press, 2007. $614 \mathrm{p}$.

2. Yee K.S., Chen Jei Shuan, Chang A.H. Conformal finitedifferent time-domain (FDTD) with overlapping grids. IEEE Transactions on Antennas and Propagation, 1992, vol.40, no.9, pp. 1068-1075. doi: 10.1109/8.166532.

3. Werner D.H., Mittra R. Frontiers in electromagnetics. New York, IEEE Press, 1999. $876 \mathrm{p}$.

4. Biro O., Preis K. On the use of the magnetic vector potential in the finite-element analysis of three-dimensional eddy currents. IEEE Transactions on Magnetics, 1989, vol.25, no.4, pp. 3145-3159. doi: 10.1109/20.34388.

5. Clemens M., Weiland T. Discrete electromagnetism with the finite integration technique. Progress in Electromagnetics Research, 2001, vol.32, pp. 65-87. doi: 10.2528/PIER00080103.

6. Rezinkina M.M., Rezinkin O.L. Modeling of the electromagnetic wavefront sharpening in a nonlinear dielectric. Technical Physics, 2011, vol.56, iss.3, pp. 406-412. doi: 10.1134/S1063784211030169.

7. Rezinkina M.M. Modeling of the dendrite shape variation with applied electric field strength in poly(ethylene). Technical Physics Letters, 2000, vol.26, iss.3, pp. 196-198. doi: 10.1134/1.1262789.

8. Berenger J.-P. A perfectly matched layer for the absorption of electromagnetic waves. Journal of Computational Physics, 1994, vol.114, no.2, pp. 185-200. doi: 10.1006/jcph.1994.1159.

9. Taflove A., Hagness S.C. Computational Electrodynamics: the Finite-Difference Time-Domain Method. Boston - London, Artech House, 2000. 852 p.

10. Zhou Z., Chen K., Zhu B., Zhao J., Feng Y., Li Y. UltraWideband Microwave Absorption by Design and Optimization of Metasurface Salisbury Screen. IEEE Access, 2018, vol.6, pp. 26843-26853. doi: 10.1109/access.2018.2835815.

11. Bottauscio O., Chiampi M., Manzin A. Numerical analysis of magnetic shielding efficiency of multilayered screens. IEEE Transactions on Magnetics, 2004, vol.40, iss.2, pp. 726-729. doi: 10.1109/tmag.2004.825171.

Received 12.04.2019

M.M. Rezinkina, Doctor of Technical Science, Professor,

${ }^{1}$ National Technical University «Kharkiv Polytechnic Institute»,

2, Kyrpychova Str., Kharkiv, 61002, Ukraine,

e-mail: maryna.rezynkina@gmail.com

How to cite this article:

Rezinkina M.M. Calculation of electromagnetic fields in inhomogeneous media for selection of protective coatings. Electrical engineering \& electromechanics, 2019, no.5, pp. 31-34. doi: 10.20998/2074-272X.2019.5.05. 